\title{
Direct LiCl-Promoted Insertion of Zinc into Organic lodides and Bromides
}

organozinc reagents

zinc insertion

lithium chloride

catalysis

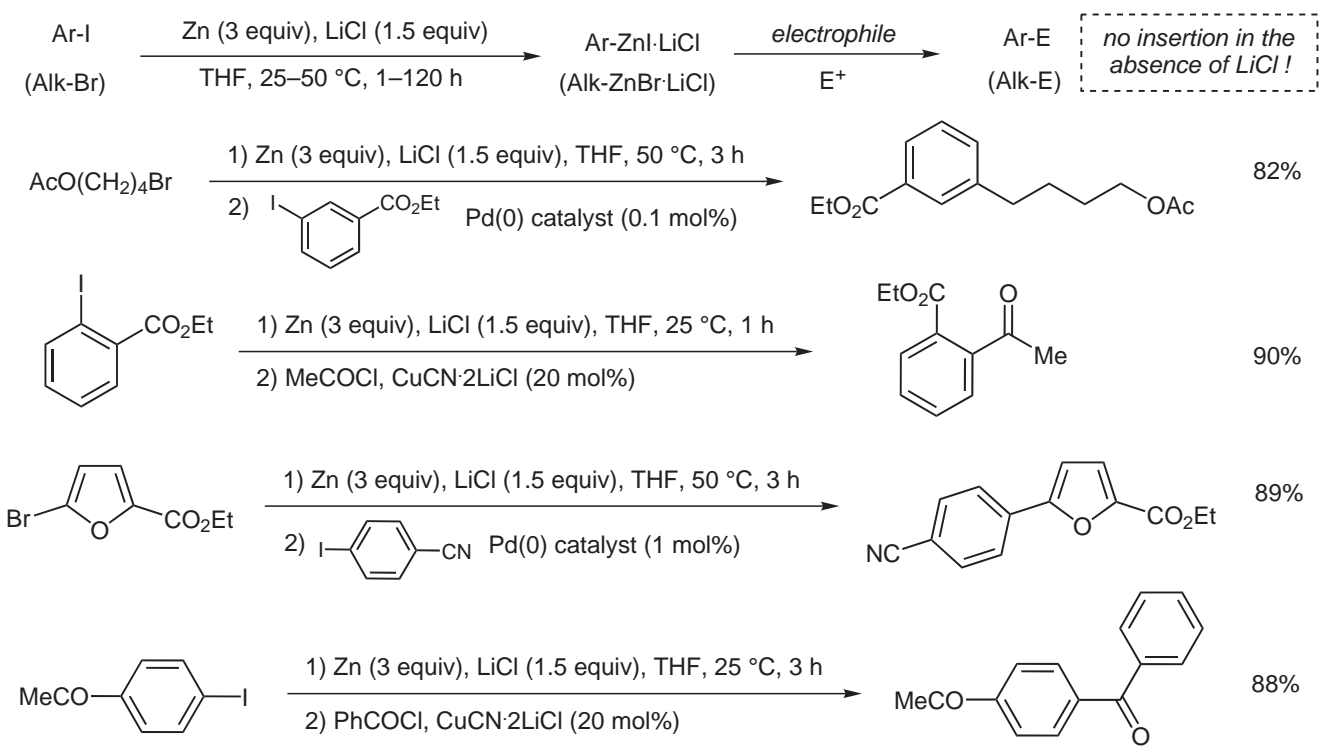

Significance: Organozinc compounds are very useful intermediates in synthesis of complex organic molecules due to their high reactivity combined with an excellent tolerance of functional groups. So far, the direct insertion of commercial zinc dust into organic halides was limited only to alkyl iodides and tertiary bromides, which diminished its synthetic value. Herein, a new method, allowing the preparation of aryl- and hetarylzinc iodides, alkyl- and several arylzinc bromides by the direct insertion of cheap metallic zinc into the corresponding halides, is reported. Inexpensive $\mathrm{LiCl}$ serves as an efficient promotor of this insertion. The resultant organozinc reagents react with various electrophiles, affording excellent yields of products.
Comment: Direct insertion of $\mathrm{Zn}$ into non-activated aryl iodides can be accomplished either at high temperature in dipolar aprotic solvents or by using activated Rieke zinc. Both ways are expensive and not convenient for scaled-up reactions. $\mathrm{LiCl}$ was found to accelerate significantly a number of reactions involving organometallics like the halogen-magnesium exchange (A. Krasovskiy, P. Knochel Angew. Chem. Int. Ed. 2004, 43, 3333-3336), supposedly by prevention of the formation of unreactive oligomers and formation of chloride atecomplexes.

Review: For a recent review on organozinc chemistry, see: P. Knochel, H. Leuser, L.-Z. Gong, S. Perrone, F. F. Kneisel In Handbook of Functionalized Organometallics, Vol. 1, P. Knochel, Ed.; Wiley-VCH: Weinheim, 2005, 251-346. 